\title{
メチレンブルー吸着法によるプラスチック表面の劣化度試験法
}

(昭和 62 年 4 月 21 日受理)

$$
\text { 馬場二夫* 細川 守* 山田明男* }
$$

\section{Evaluation of Degree of Deterioration of Plastics Surfaces by the Methylene Blue Adsorption Method}

\author{
Tsugio BaBA*, Mamoru Hosokawa* and Akio Yamada* \\ (Osaka City Institute of Public Health and Environmental \\ Sciences; 8-34, Tojo-cho, Tennoji-ku, Osaka, Japan)
}

\begin{abstract}
Plastics have been used widely for food-related household products such as tableware. These products deteriorate with the passage of time owing to the actions of oxygen, light, heat and other chemical or physical factors. Thus, consideration should be given to the undesirable contamination of foods by additives and decomposed products in the plastics.

A simple method of measuring the degree of the deterioration of plastics has not pre. viously been reported. However, we found that methylene blue (MB) is not adsorbed on an intact plastic surface, but is adsorbed on a deteriorated one. On the basis of this pro. perty, a simple MB method of determining the deterioration of plastics was developed, as follows.

The plastic item was dipped in $0.2 \% \mathrm{MB}$ solution. After five minutes, the solution was discarded and the item was rinsed in tap water. The adsorbed MB was completely recovered from the stained sample by $4 \%$ acetic acid extraction for 20 minutes. The optical density (OD) of the eluate was measured with a spectrophotometer at the wavelength of $665 \mathrm{~nm}$.

The results obtained by the MB method for 76 items of tableware showed that the OD levels of the eluates from the samples were well correlated with the visually estimated degree of deterioration, and indicate that the method is useful for the quantitative evalua. tion of plastics deterioration.
\end{abstract}

(Received April 21, 1987)

Key words: プラスチック plastics; 劣化度試験 deterioration test; 食器 tableware; メチレンブ ルー吸着 methylene blue adsorption

\section{はじめに}

プラスチックは食品関係のものに限っても, 器具, 容 器包装は言うに及ばず, 食品の製造, 加工機器などにも 広く使用されている。しかしながら，プラスチックは合 成高分子化合物並びに種々の添加剤から成る有機物質で あるが故に，ガラス，陶磁器，金属などと異なり，一般 的には長期にわたる物理的, 化学的な作用で劣化を受け ることは避けられない11 11).

現在合成樹脂製の器具, 容器包装については, 食品衛

\footnotetext{
* 大阪市立環境科学研究所：大阪市天王寺区東上町 8 $-34$
}

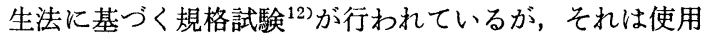
前の新品についてのみ行わ㞦ているのが実態である.し かし，日常何年かにわたって使用しているすのの中に は, 肉眼的にも明らかに劣化していると判るものがしば しば見受けられる．このような製品の場合溶出物が懸念 されるところであるが，これまでに劣化したプラスチッ クの溶出物について検討した報告は極めて少ない(13).14).

プラスチック製品は年々製造技術が進歩して怙り, 優 れた特性のものが造られてきているが，市販品にはそれ らの耐久年限は明示されて搞らず，廃棄するかどらかは 消費者個々の判断に委ねられている. 今日プラスチック は生活に欠かせない存在となっているが，長期にわたっ 
Table 1. Visual Estimation of Deterioration Progress or Roughness of Tablewares by Seven Testers

\begin{tabular}{|c|c|c|c|c|c|c|c|c|c|c|c|}
\hline \multirow{2}{*}{ Sample } & \multirow{2}{*}{ Material } & \multicolumn{7}{|c|}{ Judge } & \multicolumn{3}{|c|}{ Classification } \\
\hline & & A & B & $\mathrm{C}$ & $\mathrm{D}$ & $\mathrm{E}$ & $\mathrm{F}$ & $\mathrm{G}$ & 0 & $\triangle$ & $x$ \\
\hline Dish (a) & M F & $\times$ & $\times$ & $x$ & $\triangle$ & $x$ & $\triangle$ & $x$ & 0 & 2 & 5 \\
\hline (b) & P F & $\times$ & $x$ & $\times$ & $\triangle$ & $x$ & $x$ & $x$ & 0 & 1 & 6 \\
\hline Rice bowl (a) & M F & $x$ & $x$ & $x$ & $x$ & $\triangle$ & $x$ & $\triangle$ & 0 & 2 & 5 \\
\hline (b) & P P & $x$ & $x$ & $x$ & $x$ & $\triangle$ & $x$ & $x$ & 0 & 1 & 6 \\
\hline Tupper ware (a) & $\mathrm{PP}$ & $\triangle$ & $x$ & $x$ & $\triangle$ & $\triangle$ & $x$ & $x$ & 0 & 3 & 4 \\
\hline (b) & P E & $x$ & $x$ & $x$ & $\triangle$ & $\triangle$ & $x$ & $x$ & 0 & 2 & 5 \\
\hline Cup & P S & $\triangle$ & $\times$ & $x$ & $x$ & $\triangle$ & $x$ & $\triangle$ & 0 & 3 & 4 \\
\hline Lunch box & P P & $\times$ & $x$ & $x$ & $\triangle$ & $\triangle$ & $x$ & $x$ & 0 & 2 & 5 \\
\hline Soup bowl (a) & P F & $x$ & $x$ & $x$ & $x$ & $x$ & $x$ & $x$ & 0 & 0 & 7 \\
\hline (b) & P F & $x$ & $x$ & $\triangle$ & $x$ & $\triangle$ & $x$ & $\triangle$ & 0 & 3 & 4 \\
\hline
\end{tabular}

MF: Melamine resin; PF: Phenol resin; PP: Polypropylene; PE: Polyethylene; PS: Polystylene

$\bigcirc$ : The sample which are observed as intact as new ones.

$\triangle:$ The sample which slight deterioration or roughness are observed.

$x$ : The sample which remarkable deterioration or roughness are observed.

て使用されるものがますます多くなると予測される．こ のような状況のもとでは, 器具, 容器包装の安全性も劣 化と溶出物との関連性から検討することが重要になると 考えられる. しかし，プラスチックなど高分子化合物の 劣化の状況を簡易に測定する方法はまだ一般化されてお らず，GPC，NMR，IR など高度の機器を用いなければ ならない状況にある11).

この度, 劣化したプラスチック表面の顕微鏡写真を撮 る過程で, 塩基性染料の一つであるメチレンブルー ${ }^{13}$ が，プラスチックの劣化した部分にのみ特異的に吸着さ れる性質のあることを見出した. 従って，これを食器な どプラスチック製品の表面劣化の簡易測定法として応用 するための検討を行い，いくつかの知見を得たので報告 する.

\section{実験方法}

\section{1. 試料}

プラスチック製食器で未使用（新品）のもの，及び事 業所, 病院など集団給食施設並びに一般家庭に拈いて長 期にわたり使用されてさたもの ${ }^{14)}$ を用いた。この他に未 使用の食器あるいはプラスチックの試験片を一定期間室 温で次亜塩素酸ナトリウム溶液に浸漬処理したものを対 象とした.

材質の種類はポリエチレン (PE), ポリプロピレン (PP), ポリスチレン (PS), ポリ塩化ビニル (PVC), ポリ カーボネート (PC), ナイロン (PA), AS 樹脂 (AS), EVA 樹脂 (EVA), ポリエステル (PET), メラミン樹脂 (MF), フェノール樹脂 (PF) である.この他に汁わんな ぞのように表面に樹脂塗装したもの $(\mathrm{P})$ も若干含まれて いる.

\section{2. 試 薬}

$0.2 \%$ ×レンブルー (MB) 溶液: MB（特級） $2 \mathrm{~g}$ を 10\%エタノールに溶かして $1,000 \mathrm{ml}$ とした.

$4 \%$ 酢酸: 水酢酸 (特級) $40 \mathrm{ml}$ を水に溶かして 1,000 $\mathrm{ml}$ とした.

次亜塩素酸ナトリウム溶液：市販の次亜塩素酸ナトリ ウム溶液の原液（有効塩素 $5 \%$ ）を水で 5 倍に希釈した ものを用いた。

\section{3. 装}

自記分光光度計：島津製作所製，UV-240 型

遠心式粉砕機：日本精機 (侏) 製 ZM-1 型

\section{4. 試料の表面状態の肉眼的評価法}

試料の表面状態について，それが劣化によるものか単 なる傷であるのかを判別することすら肉眼的には難しい ことが多い，従って，ここではそのいずれも含めた外観 を肉眼的観察により次の 3 段階に区分して評価した。

すなわち，表面が滑らかで光沢のある試料を○，光沢 が失われ，傷その他の荒れがわずかにみられるものを $\triangle$ ，著しく荒れた状態のものを×とした．試料は洗剤を 用いて十分に洗浄したものを判定に供した. 試料の区分 は 7 人の判定員の評価結果の数により決めた. Table 1 は×と区分した試料についての 7 人の判定員による評価 を例示したものである。

\section{5. 劣化度測定操作法}

試料はあらかじめ洗剤で十分に洗浄し, 容器などの試 料では MB 溶液を満たし, 試料片の場合は適量の MB 溶液に試料を浸漬し， 5 分間放置した後流水で約 20 秒間 洗い，吸着していない MB を除去する。容器などの試 料はこれに $4 \%$ 酢酸を満たし, 試料片では表面積 $1 \mathrm{~cm}$ 当り $2 \mathrm{ml}$ の割合の $4 \%$ 酢酸に浸して 20 分間放置し, 吸 
着されていた MB を溶離させる.この溶離液について, 分光光度計を用い $4 \%$ 䣫酸を対照として波長 $665 \mathrm{~nm}$ に拈ける吸光度を測定する。な抏，容器などの試料の吸 光度は溶離液 (4\% 酢酸) を満たしたときの接触表面積 を測定し ${ }^{16)}$, 溶離液と表面積の比を $2 \mathrm{ml} / \mathrm{cm}^{2}$ に換算し て表示した.

\section{6. プラスチックの劣化促進のための次亜塩素酸ナ トリウム溶液処理}

各種材質の未使用の容器あるいは試験片について, そ れぞれの表面をできる限り短期間に劣化させることを目 的として以下のように次亜塩素酸ナトリウムによる劣化 促進処理を行った. すなわち, PF 及び MF 製容器につ いては次亜塩素酸ナトリウム溶液を満たし，その他の材 質のプラスチックについては縦, 横 $2 \times 5 \mathrm{~cm}$ の試験片 を次亜塩素酸ナトリウム溶液中にガラス棒などで浮かな いよう固定し，室温で 7，15，30，60日間それぞれ放置 した.このほかに PF, MF 以外の試料については同溶 液中で $95^{\circ} ， 30$ 分間浸漬した試料も調製した。 また， MF 製食器については試料を遠心式粉砕機で 120〜150 メッシュに粉砕し, 室温で 1 昼夜次亜塩素酸ナトリウム 溶液に浸漬した後, 十分に水洗したものも調製した.

\section{結果及び考察}

\section{MB 溶液の濃度と操作の再現性}

試料として約 5 年間実際に使用した MF 製どんぶり， 汁わん，及び皿を用い， $0.05 \% ， 0.1 \%$ 及び $0.2 \%$ 各 濃度の $\mathrm{MB}$ 溶液について, MB 吸着量の変動並びに操 作の再現性を検討した (Table 2). その結果，いずれの 試料に扣いても MB 溶液の濃度が低くなるに従い, 溶 離液の吸光度で示した $\mathrm{MB}$ の吸着量は少なくなるが, 各試料間の吸光度の比は $\mathrm{MB}$ 溶液の濃度が異なっても, ほとんど変らないことがわかった。 また，いずれの MB 溶液濃度に拈いても，2 回の繰り返し操作に打ける吸光
Table 2. Effects of the Concentration of Methylene Blue Solution on the Reproducibility of Adsorption and the Absorbance of the Eluates at the Wave Length of 665 $\mathrm{nm}$

\begin{tabular}{cccc}
\hline \multirow{2}{*}{ Sample } & \multicolumn{3}{c}{ Concentration of $\mathrm{MB}(\%)$} \\
\cline { 2 - 4 } & 0.05 & 0.1 & 0.2 \\
\hline Bowl & $0.146^{*}$ & 0.180 & 0.225 \\
& 0.166 & 0.170 & 0.200 \\
Soup bow1 & 0.203 & 0.237 & 0.272 \\
& 0.205 & 0.268 & 0.260 \\
Dish & 0.527 & 0.682 & 0.716 \\
& 0.514 & 0.645 & 0.720 \\
\hline
\end{tabular}

* Absorbance at the wave length of $665 \mathrm{~nm}$

度の值は近似しており，良好な再現性が得られた。

なお, $\mathrm{MB}$ 溶液の濃度が $0.2 \%$ より濃いと, 吸光度の 測定時に溶離液を希釈する必要のあるものが多くなる. また，逆に薄くし過ぎると表面に吸着された色素の肉眼 的な判別が難しくなる. 従って，本実験においては $0.2 \%$ 溶液を用いることにした.

\section{2. 表面状態についての 肉眼的評価と本法による劣化 度測定結果との比較}

表面状態の肉眼的評価 3 区分の代表的試料各 9 種類に つい, MB の吸着状況を測定した結果は Table 3 に 示したと就りである.むた，Fig. 1 には数年にわたり使 用した合成樹脂製食器76試料のうち塗装した汁わんを除 く単一樹脂製の 40 試料についての表面状態を, 前記 $\bigcirc$, $\triangle, \times の 3$ 段階に区分し，各区分別に本法による $\mathrm{MB}$ 吸着量の分布状況を示した. 同様に Fig. 2 には塗装し た汁わん36試料についての分布状況を示した.

Table 3. Optical Dencity of Methylene Blue in the Eluate from the Typical Samples which are Classified into Three Groups by Their Surface States

\begin{tabular}{|c|c|c|c|c|c|c|c|c|}
\hline & 0 & & & $\triangle$ & & & $x$ & \\
\hline Sample & Material & O.D. & Sample & Material & O.D. & Sample & Material & O.D. \\
\hline Soup bowl (a) & P F & 0.021 & Soup bowl (d) & $\mathrm{P}$ & 0.086 & Soup bowl (g) & $\mathrm{P}$ & 1.413 \\
\hline (b) & $\mathrm{P}$ & 0.033 & (e) & P A & 0.117 & (h) & P F & 1.152 \\
\hline (c) & $\mathrm{P}$ & 0.120 & (f) & P F & 1.100 & (i) & $\mathrm{P}$ & 1.026 \\
\hline Lunch box (a) & P P & 0.033 & Dish & P P & 0.107 & Dish & MF & 0.552 \\
\hline Cup & P P & 0.031 & (c) & MF & 0.039 & Lunch box (c) & P P & 0.415 \\
\hline (b) & P S & 0.035 & Tupper ware (a) & P P & 0.172 & Tupper ware (c) & $\mathrm{P} P$ & 0.906 \\
\hline Dish (a) & MF & 0.029 & Lunch box (b) & P P & 0.044 & Cup (c) & P S & 0.345 \\
\hline Tea cup (a) & MF & 0.052 & Tea cup (b) & MF & 0.328 & Rice bowl (b) & $\mathrm{PP}$ & 1.682 \\
\hline Bowl (a) & MF & 0.007 & Rice bowl (a) & MF & 0.096 & (c) & MF & 1.385 \\
\hline
\end{tabular}

Classification of the samples $(O, \Delta, \times)$ are same to Table 1 . 


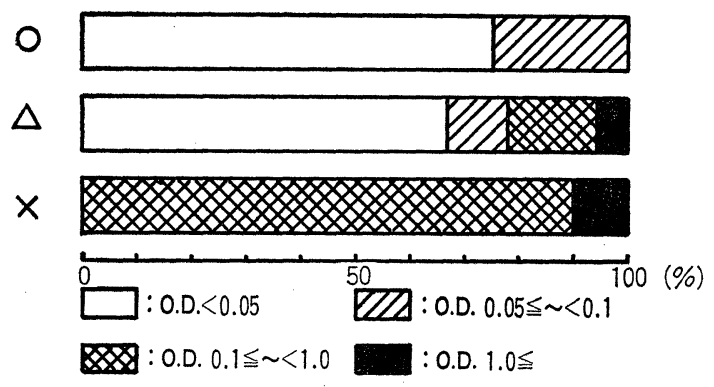

Fig. 1. Distribution of optical density (O.D.) of methylene blue which were eluted from 40 plastics tablewares used for several years with $4 \%$ acetic acid, and visual classification of their surface condition Surface condition was classified as follows. $O$ : evaluated as intact as new wares $\triangle:$ slight deterioration or roughness observed $X$ : remarkable deterioration or roughness observed

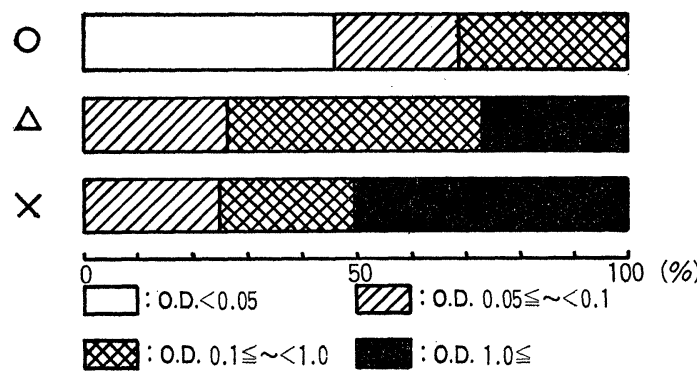

Fig. 2. Distribution of O.D. of methylene blue which were eluted from 36 painted tablewares used for several years with $4 \%$ acetic acid, and visual classification of their surface condition

Classifications are the same to Fig. 1.

* Species of paints were not clear.

Table 3, Fig. 1, Fig. 2, に示したように, ○区分の 試料は $\mathrm{MB}$ の吸光度が 0.05 未満のものが圧倒的に多 く, ことに, Fig. 1 に示したように, 単一樹脂の場合, $75 \%$ が吸光度 0.05 末満であり，0.1 以上のものはみられ なかった。

一方, $\times$ 区分の試料は吸光度 $0.1 \sim 1.0$ 範囲のものが 最も多く, なかでも単一樹脂製品の場合吸光度 0.1 以下 のものはみられなかった (Fig. 1). これに対し, $\triangle$ 区分 のものは吸光度 0.05 未満のものから 1.0 以上のものま で広範囲にまたがっていた。これは後で述べるように， 実際には材質は劣化していなくても, 固いタワシでこす ったよらな微細な傷は, 肉眼的には表面の荒れとして観
察されることなども一つの要因になっているものと考え られる. 塗装品の場合は Fig. 2 に示したように, いず れの区分においても Fig. 1 に示した単一樹脂製品に比 べ吸光度の高いものの割合が多くなっている.しかし， この場合も区分によって吸光度に明らかな差のあること がわかる.

これらの結果からみて，細部的にはいくつか問題はあ るとしても，表面状態についての肉眼的評価と吸光度で 示した MB の吸着量との間にはかなりの相関があると いえる。

\section{3. 表面の人為的な傷に対する MB の吸着状況}

古くなって表面の荒れた試料に MB の着色が見られ る現象について，それが吸着によるものなのか，微細な 割れ目への単なる $\mathrm{MB}$ の浸透によるものかについて検 討した. 試料として MF, PF, PP, PE, PS, AS, PC, PET, PVC 各材質の新しい試験片 $(5 \times 5 \mathrm{~cm})$ を用い, 各試験片にナイフで $1 \sim 2 \mathrm{~mm}$ 間隔で縦横に切傷を付け たものと，傷を付けないものについて MB の染色状況 を比較検討した. その結果, $\mathrm{MF}, \mathrm{PF}$ を除く他の試験片 は傷の有無に関わらず，すべて吸光度 0.01 未満で MB の吸着は認められなかった. $\mathrm{MF}, \mathrm{PF}$ の場合は傷を付け ないものでは吸光度 0.01 未満であったが，傷を付けた ものは深い傷の部分程濃く着色し, 吸光度も0.05 前後 で，わずかではあるが傷による影響が認められた。

これらの結果から，古くなった表面が MB によって 青色に着色するのは亀裂への単なる浸透によるものでは ないことを示していると考える. MF, PF の場合はもと もと表面と内部では重合度に違いがあるので，深い傷を 付けた場合には MB を吸着しや寸い重合度の低い部分 が露出することによるものと推定される.

\section{4. 次亜塩素酸ナトリウム処理による表面劣化と MB} 吸着状況の变化

PE 他 6 種類の材質の試料片を次亜塩素酸ナトリウム 溶液に室温で $0 〜 60$ 日間浸漬したもの，同溶液で $95^{\circ}$, 30 分間加熱したもの，及び表面を金属ブラシで傷付 けたものについて MB の吸着状況の変化を調べた結 果, Fig. 3 に示したように処理日数が長くなるに従って MB の吸着量は増大した。 また，95，30 分間加熱した ものでは PP 及び PET への吸着が特に著しかった。し かし，単に傷付けただけの試験片 (Fig. 3 の最下段)で は MB の吸着は全くみられなかった。

また，Fig. 4 に示したように PP, PE, EVA, PC に ついては処理日数の長さに対して吸光度が増える割合は 比較的ゆるやかであるが, PF, MF の場合は指数関数的 な増加を示した．このことは $\mathrm{PF}, \mathrm{MF}$ が次亜塩素酸ナ トリウム溶液に極めて侵されやすいのに対し，それ以外 のものは常温では比較的耐薬品性があることを示唆して いるものと考觉る.

一方, 粉砝した MF 試料について MB の吸着度合を 


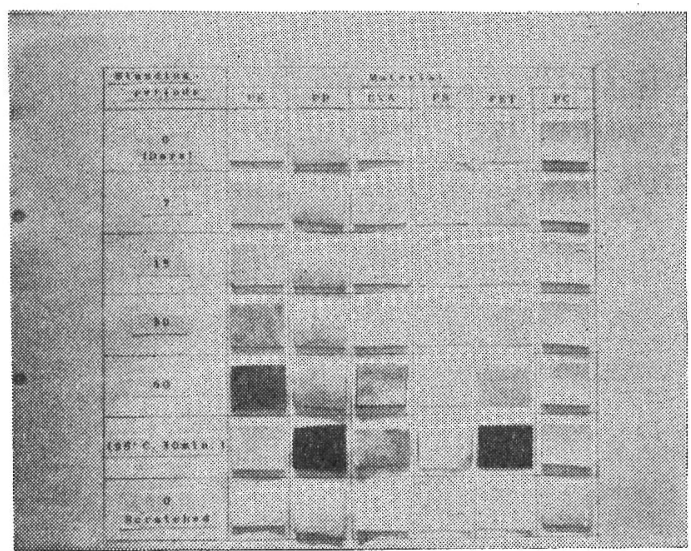

Fig. 3. Increasing of adsorption of methylene blue to plastics which treated in hypochloride solution for several periods

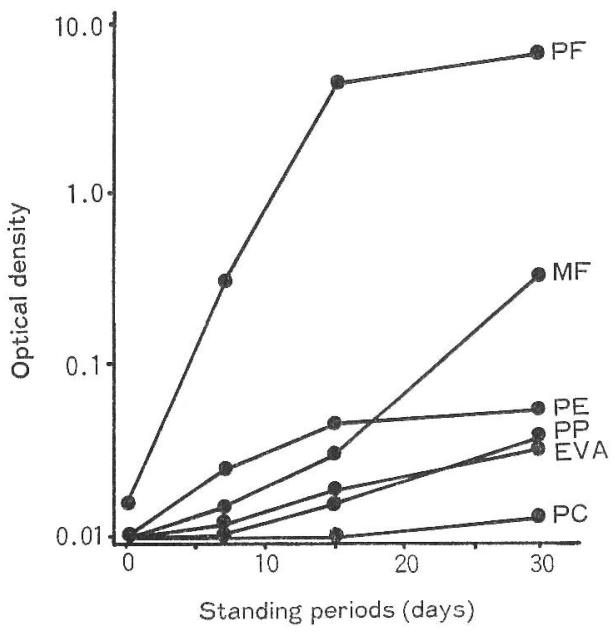

Fig. 4. Relationship between the optical density, the amounts of adsorbed methylene blue and standing periods in the solution of sodium hypochloride

比較した結果，次亜塩素酸ナトリウムで処理しないるの ではわずかな青色がみられるだけであったが，処理した ものは鮮やかな青色に着色した。 このことは, 前項とも 関連して古くなった試料に対する MB による着色は, 表面の微細な亀裂への MB の浸透によるのではなく, 劣化した部分への吸着で另ることを示唆しているものと
考光られる.

本帘験では人為的な劣化の促進法として, 次覀塩素酸 ナトリウム溶液で処理した場合についてのみ検討した 占, 今後さらに日光 (紫外線), 熱, 放射線, 微生物その 他の影響による劣化に詨する本法の適用の是非などを検 討す当必要が放る。

さらに，ポリマーの劣化度の簡易湘定法として本法が 有效であることを裏付けるためたは，ポリマーの重合度 など物理的, 化学的指禋と本法による吸光度との相関,

主びに，他の劣化試験法による結果との比較などが必要 之考光る。

な和，本報告の一部は日本食品衛生学会第50回学術諩 演会 (1985，新潟）において報告した。

\section{文献}

1) 栗原福次：“プラスチックの劣化”（1970）日刊工 業新聞社.

2)電気学会有機材料劣化専門委員会編：“高分子材 料の劣化”(1958) ロ口十社。

3) 稲葉弥之助, 飯山比吕美訳： M. B. Neiman 著 “高分子の劣化一その機構と防止法一” (1967) 産 業図書。

4) 田島守隆：壏化ビニルとポリマー 11 (10), 17〜 25 (1972).

5) 䍍藤隆一：同上 $11(10), 33 \sim 44$ (1972).

6) 键谷 勤, 荻原 幸: 同上 $\mathbf{1 1}(12), \quad 33 \sim 40$ (1972).

7）践谷 勤，酉本清一：高分子加工， 32，15 20 (1983).

8) 井川房欣：食品工業 7 下，101 109 (1970).

9) 大石不二夫：“プラスチックの耐久性” (1975) 工 業調查会。

10）奥田 聰：色材. 53，362 368 (1980).

11) 西岡篤夫, 森 定雄, 藤原 譲, 村元昭应, 中村 茂：㐱んせき 30，338～344 (1977).

12) 厚生省告示第 20 号, 昭和 57 年 2 月 16 日付官報.

13) 馬場二夫, 他: “続食品容器包装器具衛生解説” p. 207 219（1977） 日本衛生技術研究会.

14）馬場二夫, 細川守, 山田明男：食衛誌。 27 , $311 \sim 315$ (1986).

15）化学大辞典編集委員会編：“化学大辞典 9” (1971) 共立出版 (株)。

16) 日本薬学会編：“衛生試験法・注解” p. 566 567 (1980) 金原出版。 